\title{
Analisis Kestabilan Aliran Fluida Viskos Tipis pada Model Slip di Bawah Pengaruh Gaya Gravitasi
}

\author{
Sri Sulasteri*
}

\begin{abstract}
Abstrak
Hal yang selalu menjadi perhatian dalam lapisan fluida tipis adalah masalah ketidakstabilan aliran fluida, berupa terbentuknya finger pada garis kontak, daerah dimana fase padat, cair, dan gas bertemu. Tulisan ini membahas tentang analisis kestabilan aliran fluida viskos tipis pada suatu bidang inklinasi, dibawah pengaruh gaya gravitasi dengan mengunakan model slip. Adapun parameter yang digunakan adalah pengaruh gravitasi, sudut kontak, dan parameter slip. Simulasi numerik menunjukkan bahwa gaya gravitasi memberi pengaruh terhadap kondisi kestabilan aliran fluida.
\end{abstract}

Kata Kunci: Bidang inklinasi, garis kontak, gravitasi, model slip, sudut kontak.

\section{Pendahuluan}

Aliran fluida berbentuk suatu lapisan tipis adalah hal yang dapat ditemukan dalam banyak bidang, antara lain lapisan jantung dan kornea mata (bidang medis/biologi), lapisan (cat) pada dinding (bidang teknik), serta pembuatan mikrochip (bidang industri). Hal yang selalu menjadi perhatian dalam lapisan fluida tipis adalah masalah ketidakstabilan aliran fluida; dalam banyak kasus, bagian depan dari fluida (front) membentuk profil berbentuk finger atau rivulets. Kondisi seperti ini seringkali tidak diinginkan.

Salah satu contoh lapisan fluida tipis sederhana adalah aliran fluida yang mengalir di atas suatu bidang inklinasi yang dipengaruhi oleh gaya gravitasi. Salah satu aspek penting dari model ini adalah kelakuan dari fluida pada bagian depan dari bidang inklinasi, yaitu daerah di mana fase padat, cair, dan gas bertemu, yang dikenal sebagai garis kontak (contact line). Hasil-hasil percobaan menunjukkan bahwa beberapa saat setelah fluida dilepaskan, garis kontak menjadi tidak stabil jika diberikan gangguan pada arah melintang (Kondic, 2003).

Salah satu teori tentang fluida menyatakan bahwa ketika suatu fluida viskos bertemu dengan suatu permukaan padat, maka model yang tepat untuk kondisi batasnya adalah kondisi tidak-slip pada batas padat-cair (Bertozzi, 1998). Akan tetapi, penggunaan kondisi tidak-slip pada masalah lapisan fluida tipis yang sedang dikaji, tidaklah dapat diterapkan karena akan menyebabkan masalah singularitas pada garis kontak. Ada dua metode yang mungkin diterapkan untuk mengatasi masalah singular ini, yaitu dengan menggunakan prekursor berupa suatu fluida, atau dengan memberikan kondisi slip pada permukaan padat (Spaid dan Homsy, 1996).

Tulisan ini akan membahas kondisi kestabilan dari aliran fluida yang berupa lapisan tipis yang mengalir pada bidang inklinasi dibawah pengaruh gaya gravitasi, pada model slip.

\footnotetext{
* Jurusan Pendidikan Matematika, Fakultas Tarbiyah dan Keguruan UIN Alauddin, Makassar, email: chelli_math@yahoo.co.id.
} 


\section{Model Matematika}

Model matematika dari lapisan fluida tipis dibangun dari Persamaan Kontinuitas (continuity equation) dan Persamaan Navier-Stokes, serta melibatkan faktor gravitasi sebagai gaya eksternal. Kondisi batas yang terlibat dalam masalah lapisan fluida tipis adalah kondisi batas pada dua lapis batas (interface), yaitu lapis batas fluida dengan permukaan padat (solid) dan fluida dengan udara (permukaan bebas). Pada lapis batas fluida-permukaan padat, akan digunakan parameter slip.

Dalam penurunan model, digunakan asumsi bahwa ketebalan lapisan fluida sangat kecil dibandingkan panjang bidang, serta fluida yang mengalir adalah fluida viskos dan bersifat tak mampat.

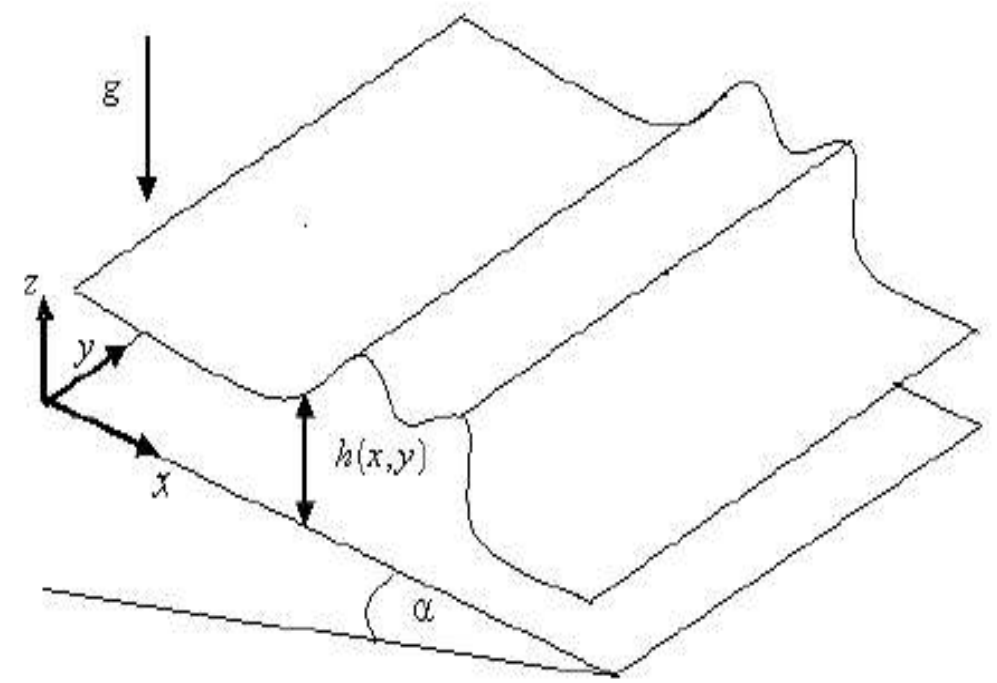

Gambar 1 . Model Lapisan Fluida Tipis yang Mengalir pada Bidang Inklinasi, di Bawah Pengaruh Gravitasi.

Selanjutnya, dengan merata-ratakan kecepatan fluida atas ketebalannya (hampiran lubrikasi), serta menggunakan kondisi batas tidak slip pada lapis batas permukaan padat-fluida, maka diperoleh persamaan lapisan fluida tipis:

$$
\frac{\partial h}{\partial t}=-\frac{1}{3 \mu} \nabla \cdot\left[\gamma\left(h^{3}+\mu \beta h\right) \nabla \nabla^{2} h-\rho g\left(h^{3}+\mu \beta h\right) \nabla h \cos \alpha+\rho g\left(h^{3}+\mu \beta h\right) \sin \alpha \mathrm{i}\right]
$$

dimana $g$ adalah gravitasi, $\rho$ densitas fluida, $\mu$ adalah viskositas fluida, $\alpha$ adalah sudut inklinasi, $\beta$ adalah konstanta slip, serta $i$ adalah vektor satuan dalam arah $x$. Persamaan (1) selanjutnya dibawa ke bentuk tak berdimensi dengan melakukan penskalaan

$$
\bar{h}=\frac{h}{h_{c}},(\bar{x}, \bar{y}, \bar{t})=\left(\frac{x}{x_{c}}, \frac{y}{x_{c}}, \frac{t}{t_{c}}\right)
$$




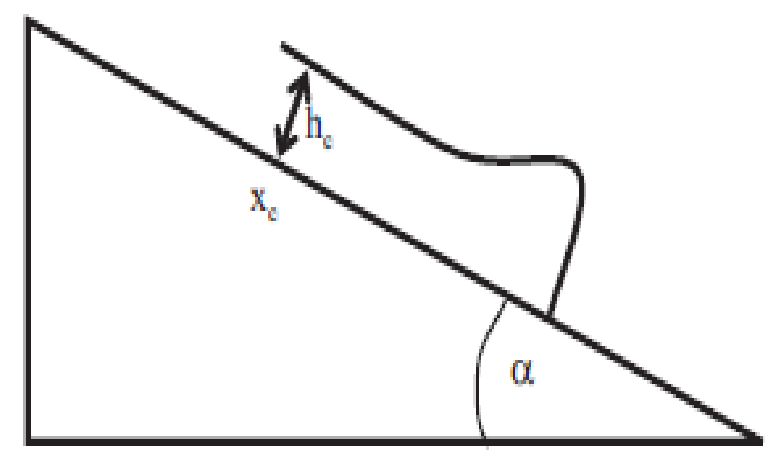

Gambar 2. Model Lapisan Fluida Tipis yang Diskalakan.

Didefinisikan panjang kapiler $a=\sqrt{\gamma / \rho g}$, dan bilangan kapiler $C a=\mu U / \gamma$. Panjang kapiler a menyatakan seberapa besar pengaruh tegangan permukaan terhadap gravitasi, sedangkan bilangan kapiler $\mathrm{Ca}$ menyatakan perbandingan antara kekentalan fluida dengan tegangan permukaan. Misalkan $U$ adalah skala untuk kecepatan dan $D(\alpha)=(3 C a)^{1 / 3} \cot \alpha$, maka dengan menggunakan skala:

$$
x_{c}=\left(\frac{a^{2} h_{c}}{\sin \alpha}\right)^{1 / 3}, t_{c}=\frac{3 \mu}{\gamma} \frac{a^{2} x_{c}}{h_{c}^{2} \sin \alpha}, U=\frac{x_{c}}{t_{c}}=\frac{1}{3 \mu} h_{c}^{2} \rho g \sin \alpha, \text { serta } \beta=\frac{h_{c}^{2}}{\mu} \bar{\beta}
$$

diperoleh persamaan lapisan fluida tipis tak berdimensi untuk model slip yaitu

$$
\frac{\partial h}{\partial t}=-\nabla \cdot\left(h^{3}+\beta h\right) \nabla \nabla^{2} h+D(\alpha) \nabla \cdot\left(h^{3}+\beta h\right) \nabla h-\frac{\partial\left(h^{3}+\beta h\right)}{\partial x} .
$$

Persamaan (4) yang selanjutnya digunakan untuk menganalisis kestabilan aliran fluida.

\section{Solusi Dasar dari Model Slip}

Jika persamaan (4) hanya dipandang sebagai persamaan dalam variabel $x$, maka diperoleh persamaan differensial parsial satu variabel:

$$
\frac{\partial h}{\partial t}=-\left[\left(h^{3}+\beta h\right) h_{x x x}\right]_{x}+D(\alpha)\left[\left(h^{3}+\beta h\right) h_{x}\right]_{x}-\left[h^{3}+\beta h\right]_{\mathrm{x}} .
$$

Kondisi slip yang digunakan pada model, menyebabkan permukaan bebas dapat bersentuhan dengan permukaan padat $(b \rightarrow 0)$. Hal ini mengharuskan adanya syarat kemiringan dari garis kontak. 


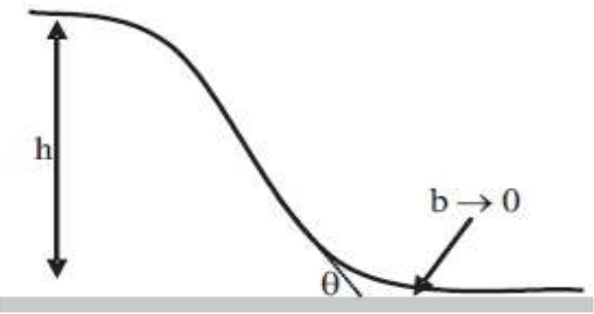

Gambar 3. Model dengan Parameter Slip.

Oleh karena itu, syarat batas yang mungkin untuk model slip adalah:

$$
h(0, t)=1, h\left(L_{x}, t\right)=0, h_{\mathrm{x}}\left(L_{\mathrm{x}}, t\right)=C(\theta)
$$

dengan $C(\theta)$ menyatakan nilai kemiringan garis kontak, yang diekspresikan sebagai fungsi dari bilangan kapiler $C a$ dan sudut kontak $\theta$,

$$
C(\theta)=(3 C a)^{-1 / 3} \tan \theta .
$$

Definisikan $h_{0}(\xi)=h(x, t)$ dengan $\xi=x-U s t$, adalah solusi gelombang berjalan dari persamaan (5), dengan syarat batas (6). Selanjutnya, diperoleh persamaan differensial biasa:

$$
h_{0 \xi \xi \xi}-D(\alpha) h_{0 \xi}-\frac{1+\beta}{h_{0}^{2}+\beta}+1=0
$$

yang menyatakan solusi dari $h_{0}(x-U s t)$ dengan $U s=1+\beta$. Solusi dasar untuk persamaan lapisan fluida tipis untuk model slip adalah solusi dari Persamaan (7). Solusi ini diperoleh dengan pendekatan numerik yaitu dengan metode beda hingga (diskritisasi dengan menggunakan empat titik), dengan melibatkan parameter slip $\beta$, kemiringan kontak $C(\theta)$, serta komponen normal gravitasi $D(\alpha)$.

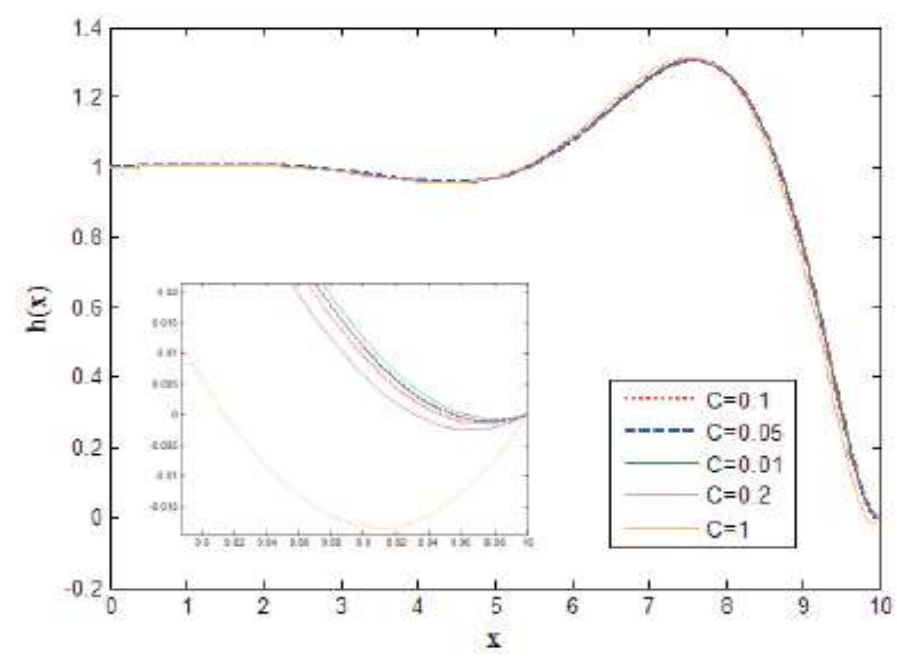

Gambar 4. Solusi $h(x)$ dengan Parameter $C(\theta)$ yang Bervariasi, $\beta=0,1$, dan $D(\alpha)=0$. 
Gambar 4 adalah grafik fungsi solusi $h(x)$ dengan parameter $C(\theta)$ yang bervariasi, dengan $\beta$ dan $D(\alpha)$ yang tetap, yaitu $\beta=0,1$ dan $D(\alpha)=0$. Gambar 4 menunjukkan bahwa untuk $C(\theta) \leq 0,1$, parameter kemiringan kontak tidak memberikan perubahan yang signifikan terhadap solusi dasar. Sedangkan untuk nilai $C(\theta)>0,1$ solusi $h(x)$ tidaklah valid, karena terdapat nilai $h(x)$ yang negatif di daerah dekat garis kontak. Hal ini disebabkan karena hampiran lubrikasi yang digunakan dalam penurunan model lapisan fluida tipis menggunakan asumsi bahwa kemiringan dari permukaan bebas haruslah kecil, yang berarti haruslah $C(\theta)<<1$. Jadi, selanjutnya hanya akan digunakan parameter $C(\theta)$ untuk $C(\theta) \leq 0,1$ dalam menguji kestabilan solusi.

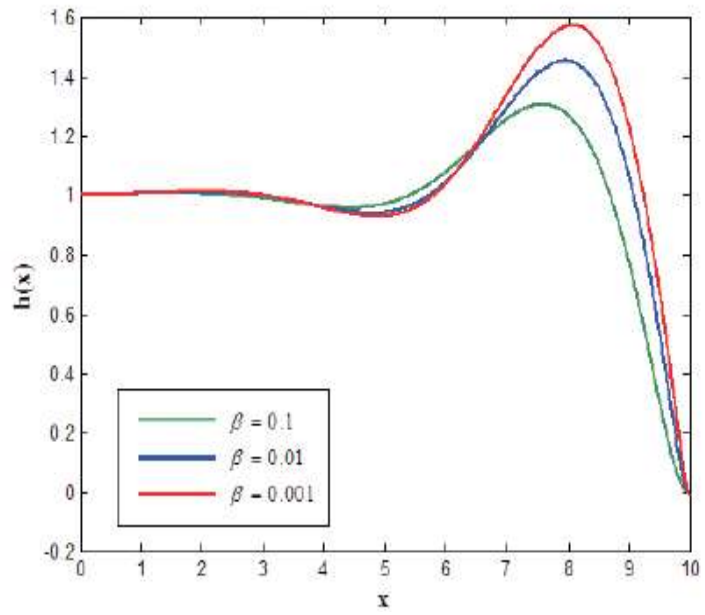

(a)

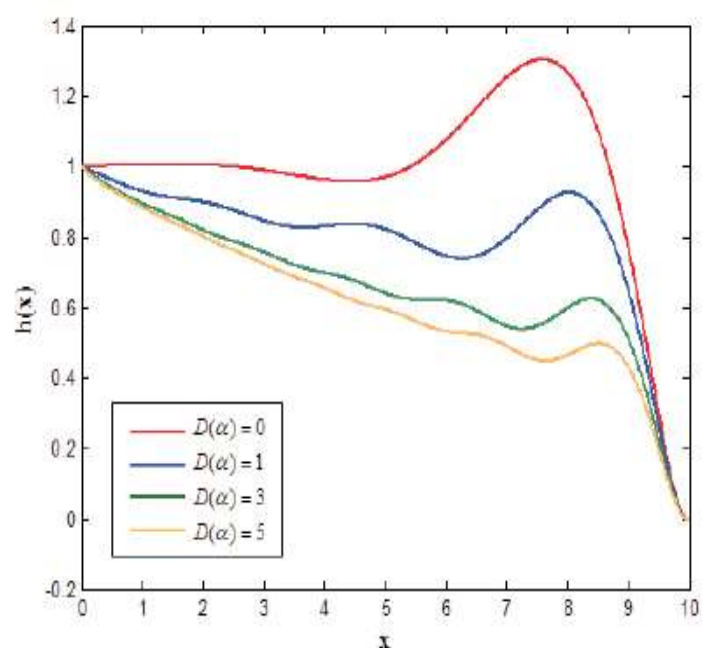

Gambar 5. Solusi $h(x)$ dengan $c(\theta)=U$, us untuk:

(a) $D(\alpha)=0$ dan $\beta$ yang Bervariasi, (b) $\beta=0,1$ dan $D(\alpha)$ yang Bervariasi.

Adapun Gambar 5 memperlihatkan profil solusi $h(x)$ dengan parameter $\beta$ dan $D(\alpha)$. Gambar 5(a) menunjukkan solusi untuk nilai parameter slip yang bervariasi, dengan kemiringan kontak $C(\theta)$ dan $D(\alpha)$ yang tetap. Profil dari grafik menunjukkan bahwa semakin kecil nilai $\beta$, maka ketinggian gundukan makin besar. Hal ini menunjukkan bahwa ada kebergantungan antara parameter slip $\beta$ dengan ketinggian gundukan dari solusi. Akan tetapi, karena terbentuknya gundukan ini menggambarkan adanya ketidakstabilan dari solusi, berarti perubahan parameter slip $\beta$ tidaklah menyebabkan solusi menjadi stabil. Sedangkan gambar 5(b) memperlihatkan peranan dari parameter $D(\alpha)$ terhadap kestabilan dari solusi dasar. Gambar ini memperlihatkan terjadinya gundukan di dekat garis kontak dari setiap grafik, yang mengindikasikan terjadinya ketidakstabilan aliran fluida. Akan tetapi dibandingkan dengan parameter $\beta$ dan $C(\theta)$, parameter $D(\alpha)$ memberikan pengaruh yang signifikan terhadap ketidakstabilan solusi $h(x)$.

\section{Analisis Kestabilan Linier}

Pandang Persamaan (4) dalam variabel $(\xi, y, t)$ dan asumsikan solusinya dalam bentuk

$$
h(\xi, y, t)=h_{0}(\xi)+\in h_{1}(\xi, y, t)
$$

dengan $\in<<1$ dan $h_{1}=O(1)$, maka Persamaan (4) menjadi: 


$$
\frac{\partial h}{\partial t}=-\nabla \cdot\left(h^{3}+\beta h\right) \nabla \nabla^{2} h+D(\alpha) \nabla \cdot\left(h^{3}+\beta h\right) \nabla h-\frac{\partial\left(h^{3}+\beta h\right)}{\partial x}+U_{s} h_{\xi}
$$

dengan $\xi=x-U s t$ dan $\nabla=(\partial \xi, \partial \mathrm{y})$.

Persamaan (8) dapat dinyatakan dalam bentuk Fourier dalam $y$, yaitu dengan mengekspresikan

$$
h_{1}(\xi, y, t)=\phi(\xi, t) e^{i q y+\sigma},
$$

dimana $q$ adalah bilangan gelombang, yang berkaitan dengan periode dari perturbasi ( $q=$ $2 \pi / \lambda$ ), sedangkan $\sigma$ adalah derajat ketidakstabilan solusi. Dengan demikian, jika diberikan suatu $q$ maka diperoleh suatu masalah nilai eigen:

$$
£ \varphi=-\sigma \varphi,
$$

dengan $£$ adalah operator linier yang memenuhi:

$$
\begin{aligned}
£= & \left(h_{0}^{3}+\beta h_{0}\right) \frac{d^{4}}{d \xi^{4}}+\left(h_{0}^{3}+\beta h_{0}\right)_{\xi} \frac{d^{3}}{d \xi^{3}}-\left(D(\alpha)+2 q^{2}\right)\left(h_{0}^{3}+\beta h_{0}\right) \frac{d^{2}}{d \xi^{2}} \\
& +\left(\left(3 h_{0}^{2}+\beta\right)\left(h_{0 \xi \xi \xi}-D(\alpha) h_{0 \xi}+1\right)-\left(h_{0}^{3}+\beta h_{0}\right)_{\xi}\left(D(\alpha)+q^{2}\right)-U_{s}\right) \frac{d}{d \xi} \\
& +\left(h_{0}^{3}+\beta h_{0}\right) q^{2}\left(D(\alpha)+q^{2}\right)+\left(\left(3 h_{0}^{2}+\beta\right)\left(h_{0 \xi \xi \xi}-D(\alpha) h_{0 \xi}+1\right)\right)_{\xi} .
\end{aligned}
$$

Analisis kestabilan solusi diperoleh dengan menyelesaikan Persamaan (9) secara numerik. Prosedur numeriknya adalah dengan mencari $\sigma$ (nilai eigen) terbesar dari setiap $q$ yang diberikan, sehingga diperoleh grafik fungsi $\sigma(q)$.

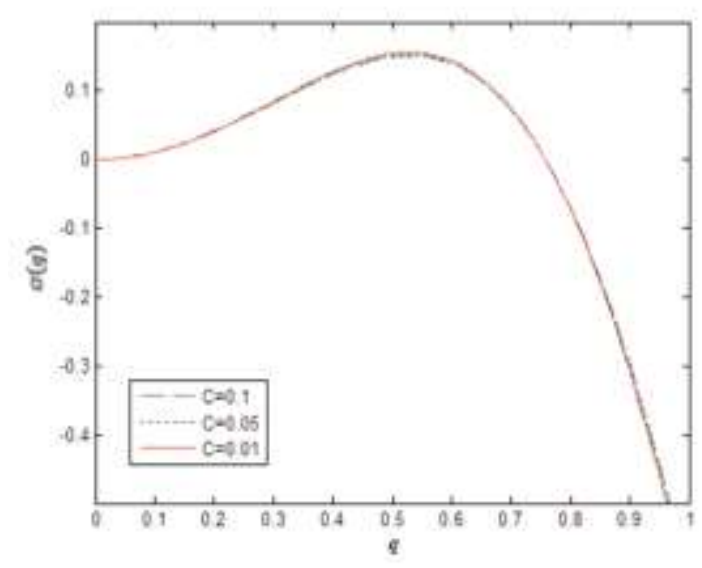

Gambar 6. Derajat Ketidakstabilan $\sigma(q)$ dengan Parameter $C(\theta) \leq 1, D(\alpha)=0, \beta=0,1$.

Gambar 6 menunjukkan bahwa untuk $C(\theta) \leq 1$, parameter kemiringan kontak tidak memberikan perubahan yang signifikan terhadap derajat ketidakstabilan. Hal ini dapat dijelaskan dengan 
memperhatikan kebergantungan $C(\theta)$ terhadap solusi dasar. Profil dari solusi dasar tidaklah sensitif terhadap perubahan $C(\theta)$ untuk $C(\theta) \leq 1$, bahkan pada daerah di sekitar garis kontak.

Gambar 7 di bawah adalah grafik fungsi $\sigma(q)$ dengan parameter $\beta$ dan $D(\alpha)$. Gambar 7(a) menunjukkan bahwa terdapat daerah dari $q$ dimana laju pertumbuhan $\sigma(q)$ bernilai positif, yaitu daerah yang dibatasi oleh $q=0$ dan $q s=2 \pi / \lambda$. Kondisi paling tidak stabil terjadi pada $q m \approx 0,5$ atau berkorespondensi dengan $\lambda m \approx 12,6$. Hasil lain yang tampak dari gambar 7(a) yaitu bahwa derajat ketidakstabilan $\sigma(q)$ bertambah jika parameter slip $\beta$ berkurang. Hasil ini bersesuaian dengan solusi dasar dari model slip, yaitu nilai maksimum dari $h(x)$ bertambah jika parameter slip $\beta$ berkurang. Adapun gambar 7(b) menunjukkan bahwa kenaikan nilai $D(\alpha)$ menyebabkan penurunan derajat ketidakstabilan $\sigma(q)$, serta pergeseran posisi dari $\sigma(q m)$ dan $\sigma(q s)$. Hasil ini sejalan dengan hasil pada solusi dasar, yaitu kenaikan nilai $\mathrm{D}(\alpha)$ menyebabkan solusi dasar lebih stabil.
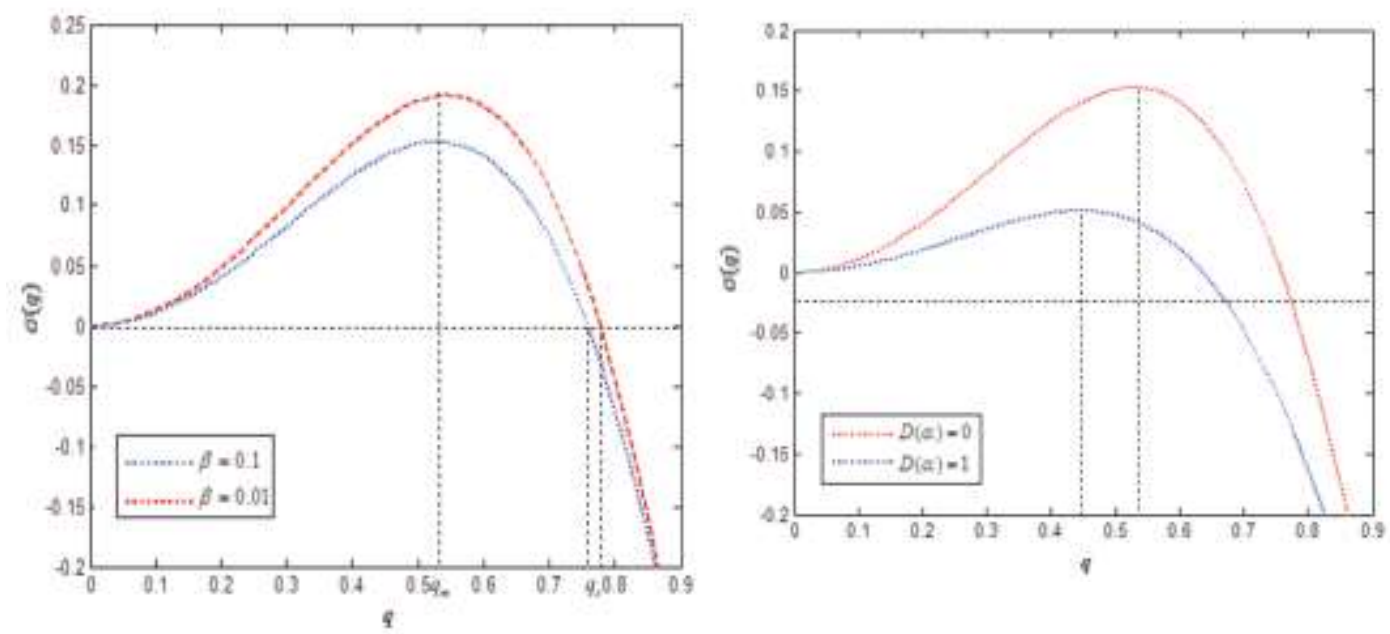

Gambar 7. Solusi $h(x)$ dengan $\mathrm{C}(\theta)=0,05$ untuk: (a) $\mathrm{D}(\alpha)=0$ dan $\beta$ yang Bervariasi, (b) $\beta=0,1$ dan $D(\alpha)$ yang Bervariasi.

\section{Kesimpulan}

Tulisan ini membahas masalah ketidakstabilan dari lapisan fluida tipis yang mengalir di atas suatu bidang inklinasi, dengan menggunakan model slip. Parameter yang digunakan adalah konstanta slip $\beta$, sudut kontak $C(\theta)$, dan komponen normal gravitasi $D(\alpha)$. Analisis yang dilakukan mengacu pada solusi dasar dari persamaan lapisan fluida tipis, serta derajat ketidakstabilan dari solusi dasar yang diperturbasi.

Simulasi numerik menunjukkan bahwa penurunan nilai parameter slip menyebabkan solusi dasar menjadi lebih tidak stabil, sedangkan kenaikan nilai $D(\alpha)$ menyebabkan profil lebih stabil. Adapun perubahan parameter $C(\theta)$ tidak memberikan perbedaan yang signifikan terhadap profil solusi dasar. Ketiga parameter ini juga memberikan efek ketidakstabilan yang sama pada derajat ketidakstabilan. Simulasi numerik juga menunjukkan bahwap parameter $D(\alpha)$ yang berkaitan dengan sudut dari bidang inklinasi (komponen normal gravitasi) mempunyai peran yang sangat besar dalam menentukan kondisi kestabilan dari solusi. 


\section{Daftar Pustaka}

Bertozzi, A.L. dan Brenner, M.P. 1997. Linear stability and transient growth in driven contact lines. Phys. Fuids, 9, pp. 530-539.

Bertozzi, A.L. 1998. The mathematics of moving contact lines in thin liquid films, Notices Amer. Math. Soc., 45, pp. 689-697.

Hoffman, J.D., 1992. Numerical Methods for Engineers and Scientists. McGraw-Hill, Inc., NewYork.

Kondic, L., 2003. Instabilities in gravity driven flow of thin fluid films. SIAM Review, Vol. 45, pp. 95-115.

Spaid, M.A. dan Homsy, G.M., 1996. Stability of newtonian and viscoelastic dynamic contact lines. Phys. Fuids, 8, No. 2. 